\title{
Colorectal Liver Metastases: A Critical Review of State of the Art
}

\author{
Robert P. Jones $s^{a, b} \quad$ Norihiro Kokudo ${ }^{c}$ Gunnar Folprecht ${ }^{d}$ \\ Yoshihiro Mise ${ }^{c}$ Michiaki Unno ${ }^{e}$ Hassan Z. Malik ${ }^{b}$ \\ Stephen W. Fenwick ${ }^{b}$ Graeme J. Poston ${ }^{b}$
}

aSchool of Cancer Studies, Institute of Translational Medicine, University of Liverpool, Liverpool,

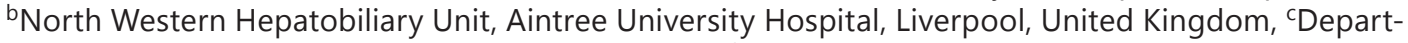
ment of Surgery, University of Tokyo, Tokyo, Japan, dUniversity Hospital Carl Gustav Carus, University Cancer Center, Dresden, Germany, ${ }^{e}$ Department of Surgery, Tohoku University Graduate School of Medicine, Sendai, Japan

\section{Key Words}

Chemotherapy · Liver cancer · Surgery

\begin{abstract}
Background: Over $50 \%$ of patients with colorectal cancer will develop liver metastases. Only a minority of patients present with technically resectable disease. Around $40 \%$ of those undergoing surgical resection are alive five years after their diagnosis compared with less than $1 \%$ for those with disseminated disease treated with systemic chemotherapy. Surgical resection remains the only possibility for long-term survival for these patients and great efforts have been made to increase the rates of resection whilst improving long-term outcomes. Summary: This review considers current technical and oncological criteria for resection, as well as targeted approaches to stratify underlying tumor biology in order to better predict long-term benefit. The role of neoadjuvant and perioperative systemic chemotherapy is critically reviewed, with suggestions for patient stratification in order to identify those who are likely to derive the greatest benefit. The key role of multidisciplinary assessment and decision making for these complex patients is also discussed. Key Messages: Surgery remains the optimal treatment for colorectal liver metastases (CRLM). Despite the curative intent of surgical resection, the majority of patients develop recurrence. Surgical strategies should therefore be adopted to maximize the potential for repeat resections in the event of recurrence. Although a number of preoperative prognostic markers have been identified, none are absolute contraindications to resection. In order to reduce postoperative recurrence, neoadjuvant chemotherapy is now the standard of care in a number of countries. The evidence
\end{abstract}


base for this approach is contentious, and the potential benefit of such a strategy is likely to be greatest in patients with high oncological risk disease. Multidisciplinary care is essential to ensure the optimal management of these complex patients. In addition, all patients with CRLM should be discussed with specialist hepatobiliary surgeons.

Copyright $(2016$ S. Karger AG, Basel

\section{Resection for Patients with Resectable Potential: Just a Technical Issue?}

Over the past two decades, treatment strategies and outcomes for patients undergoing surgery for colorectal liver metastases (CRLM) have changed dramatically. Portal venous embolization and staged hepatectomies have increased the technical resectability of patients with CRLM without compromising safety. Chemotherapeutic manipulation of metastatic disease has also improved, with perioperative treatment commonly used to convert initially irresectable disease to resectable disease [1]. These enormous advances in what surgeons consider technically resectable have led to the additional concept of oncological resectability, where long-term benefit of surgery is considered alongside the purely technical aspects of resectability [2]. Large retrospective series have identified many oncological prognostic factors including large number of lesions, tumor size, interval from primary resection and tumor progression during preoperative chemotherapy. However, none of these factors represents an absolute contraindication to surgery. Even when these negative prognosticators are present, long-term survival benefit can still be achieved compared to palliative chemotherapy [2]. The limitations of these relatively coarse surrogates of tumor biology have also been highlighted by growing evidence that conventional size-based assessments of tumor response such as Response Evaluation Criteria in Solid Tumors Criteria inadequately assess the efficacy of modern cytotoxic and biological therapeutic regimens $[3,4]$.

Despite surgery being performed with curative intent, around $65 \%$ of patients will develop intrahepatic recurrence within three years, even with the addition of systemic chemotherapy [5]. There is a growing recognition that liver-limited recurrence can be re-resected, still with good long-term outcomes. In order to maximize the likelihood of being able to perform repeat surgery, a parenchymal-sparing approach to the initial liver resection is now routinely adopted. This approach is supported by evidence that more aggressive resection at primary surgery does not prevent intrahepatic recurrence [6, 7]. Parenchymal-sparing hepatectomy becomes technically demanding in the presence of multiple CRLM or tumors located deep within the liver. However, a better understanding of the arterial, venous and biliary anatomy, coupled with improvements in ultrasound technology means that single-stage intraoperative ultrasound guided resection of multiple bilobar lesions is now technically feasible $[8,9]$. Several studies have demonstrated the efficacy of ablation therapy in local control of CRLM that are difficult to resect [10]. However, the high local recurrence rate after ablation therapy [11], highlights the critical role of surgery wherever technically possible.

\section{Neoadjuvant Chemotherapy in Resectable Patients: the Western Perspective}

Neoadjuvant and adjuvant treatment of patients with resectable CRLM is now considered as standard of care in most Western countries, even though from a truly evidence-based point of view the effect is not currently proven.

In 2008, Mitry et al. published a meta-analysis of two trials investigating bolus 5-fluorouracil (5-FU) as adjuvant therapy following resection of liver metastases. Both trials were 
performed between 1991 and 2001, and were discontinued early due to poor patient recruitment. In the meta-analysis, a trend towards better progression free survival (PFS) (hazard ratio [HR] 1.32, 95\% confidence interval [CI] 1.00-1.76, $\mathrm{p}=0.058$ ) was observed as well as a trend towards better overall survival (OS) (HR 1.32, 95\% CI 0.95-1.82; $p=0.095$ ) [12]. The 2004 Evaluation of perioperative chemotherapy (EPOC) EORTC 40983 trial randomized patients to a perioperative treatment with folinic acid-fluorouracil-oxaliplatin (FOLFOX) or surgery alone, with patients in the perioperative treatment arm receiving cycles of chemotherapy before surgery and six cycles thereafter [13]. At a median follow-up of 8.5 years, there was a trend towards better PFS (HR 0.81, 95\% CI 0.64-1.02, p=0.068) and slightly better OS (HR $0.87,95 \%$ CI $0.66-1.14 ; \mathrm{p}=0.30$ ) in the perioperative chemotherapy group. However, the trial was never powered to demonstrate an improvement in OS [14]. A formal subgroup analysis demonstrated that patients with normal carcinoembryonic antigen (CEA), decreased performance status, or a body mass index more than 30 derived little benefit from perioperative treatment, whereas those within other subgroups had hazard ratios for PFS of 0.6 [15]. The apparent relationship between CEA and the benefit from chemotherapy is intriguing, and highlights the change in patient selection for surgery since these pivotal studies were published. A significant proportion of patients included in these trials had solitary metastases with metachronous presentation, and would be considered to have relatively low oncological risk disease. Perioperative or adjuvant oxaliplatin-based therapy may therefore be of most benefit in patients with moderate or high oncological risk disease. However, upfront resection is also considered a viable option especially in patients with limited metastases [16].

The improved survival seen after adjuvant FOLFOX in stage III colorectal cancer has lead to a number of trials assessing combination therapy in stage IV disease. A study investigating folinic acid-fluorouracil-irinotecan instead of single agent 5-FU as adjuvant treatment for CRLM demonstrated no difference between both arms [17]. The New EPOC study aimed to evaluate the possible benefit of the addition of monoclonal antibody therapy against the epidermal growth factor receptor in KRAS wild-type disease by adding cetuximab to FOLFOX in the neoadjuvant setting. However, the authors reported a significantly shorter PFS for combination therapy (14.1 versus 20.5 months) [18] and this trial was intensively discussed for both the study methodology and the balance of surgery between the arms [19].

\section{Neoadjuvant Chemotherapy in Patients with Resectable Synchronous Liver Metastases - The Eastern Perspective}

Colorectal cancer is one of the most common causes of cancer death globally. More than 100,000 patients are diagnosed each year in Japan alone, of whom $25 \%$ will have liver metastases at presentation - defined as synchronous liver metastases. The optimal surgical sequencing strategy for up-front resectable synchronous metastases remains controversial and is widely debated. Simultaneous resection of the primary colorectal cancer with liver resection has been suggested as an approach to minimize impact on the patient, but some series have reported increased morbidity and mortality [20]. Alternative strategies include a "liverfirst" approach where the liver disease is resected during the initial procedure, followed by a period of adjuvant therapy, then by resection of the colorectal primary, or more traditionally, resection of the primary colorectal tumor followed by liver resection at a later date.

The evidence supporting perioperative chemotherapy for limited metachronous disease has already been described above. Synchronous disease has been widely recognized as prognostically unfavorable in various patient cohorts, and the role of neoadjuvant therapy in this higher-risk setting has not been clearly defined [21]. The Tohoku University group therefore 
performed a single arm phase II study assessing the feasibility and efficacy of neoadjuvant chemotherapy with modified FOLFOX6 (mFOLFOX6) and bevacizumab for patients with resectable synchronous CRLM-the Bevacizumab and FOlfox6 for coloRectal liver mEtastases (BeFORE) study (unpublished data).

Forty-four patients from 13 institutions were treated. After resection of the primary colorectal cancer, neoadjuvant chemotherapy with mFOLFOX6 plus bevacizumab was administered for eight cycles. Thirty four patients (77.2\%) tolerated the full eight cycles. Adverse events grade $3 / 4$ occurred in $47.7 \%$ of cases. The overall response rate was $72.7 \%$, with $90.9 \%$ of patients proceeding to liver resection. There were no perioperative deaths, and the R0 (microscopically tumor-negative margin) resection rate was $88.6 \%$. The authors concluded that treatment with mFOLFOX6 and bevacizumab was safe and feasible in a neoadjuvant setting for synchronous resectable stage IV disease, with impressive response rates. Long-term follow-up is underway to assess the outcome for patients from this trial.

\section{The Pros and Cons of Multidisciplinarity in the Management of Colorectal Cancer Liver Metastases}

The multidisciplinary management of all cancer patients is now a mandatory legal requirement in a number of European countries and in the United States. The complexity of managing advanced colorectal cancer in the second decade of the 21st century is such that multidisciplinary management is now the norm to achieve optimal outcomes. Even a decade ago, it was calculated that once the decision by the patient to receive treatment, or the patient was fit enough to be offered treatment were factored into the treatment algorithm, then there were 2.4 million permutations for the management of a patient with CRLM [22]. The question of patient fitness to undergo further surgical treatment for metastatic colorectal cancer is now crucial, as the median age at the time of diagnosis is 70 years. Historically, operative mortality following hepatectomy approached 5\% in patients over the age of 70 . However, by using preoperative cardiopulmonary testing to quantify operative risk mortality, this can be reduced to $1 \%$ even in the over-80's age group [23].

Many attempts have been made to assess the potential benefit of liver resection. The original Clinical Risk Score (CRS) used a number of preoperatively assessable factors [including size and number of lesions, CEA, and interval from primary resection] to guide prognosis after hepatectomy [21]. For patients with a CRS of 1, the median OS was over 60 months. However, patients with a CRS of 5 had a median OS of 24 months - a figure now surpassed by contemporary systemic chemotherapeutic regimens. It is therefore clear that whilst hepatic surgery offers excellent long-term survival for some patients, for others the benefit may be more marginal. There is generally broad agreement over which patients clearly should and should not be offered resection [24]. For a patient with a small solitary liver metastasis presenting several years after primary colonic resection, surgery is generally accepted to offer a clear and significant long-term survival benefit. For patients with synchronous extensive large volume disseminated disease, surgery is often considered inappropriate. Deciding on the optimal management strategy for patients who fall into the grey area between these two groups is one of the most challenging decisions in the management of CRLM, and involves a careful assessment of both technical and oncological factors. Multidisciplinary discussion and decision making is now well recognized as the optimal approach [2]. In the United Kingdom, wide variations in referral patterns for the assessment by hepatobiliary specialists have been recognized with a ten-fold variation reported between the highest and lowest referring centers [25]. The importance of multidisciplinary decision making has been further rein- 
forced by growing evidence suggesting benefit from alternative non-surgical interventions for unresectable CRLM, as highlighted by the recently updated results from EORTC 40004, which demonstrated a significant improvement in OS for patients randomized to receive ablation of liver metastases and systemic chemotherapy versus chemotherapy alone [26, 27].

Further work is needed to better identify patients who are likely to benefit the most from surgery. Existing prognostic markers rely on the gross assessment of pathology as a surrogate for underlying tumor biology. It seems likely that increased understanding of tumor biology will further improve patient stratification, thereby improving outcomes after hepatectomy by allowing better decision-making about which patients will benefit in the long-term.

\section{Disclosure Statement}

The authors declare they have no conflicts of interest.

\section{References}

1 Jones RP, Hamann S, Malik HZ, Fenwick SW, Poston GJ, Folprecht G: Defined criteria for resectability improves rates of secondary resection after systemic therapy for liver limited metastatic colorectal cancer. Eur J Cancer 2014;50:1590-1601.

2 Adam R, De Gramont A, Figueras J, Guthrie A, Kokudo N, Kunstlinger F, Loyer E, Poston G, Rougier P, RubbiaBrandt L, Sobrero A, Tabernero J, Teh C, Van Cutsem E, Jean-Nicolas Vauthey of the EGOSLIM (Expert Group on OncoSurgery management of LIver Metastases) group: The oncosurgery approach to managing liver metastases from colorectal cancer: a multidisciplinary international consensus. Oncologist 2012;17:12251239.

3 Shindoh J, Loyer EM, Kopetz S, Boonsirikamchai P, Maru DM, Chun YS, Zimmitti G, Curley SA, Charnsangavej C, Aloia TA, Vauthey JN: Optimal morphologic response to preoperative chemotherapy: an alternate outcome end point before resection of hepatic colorectal metastases. J Clin Oncol 2012;30:4566-4572.

4 Jones RP, Stättner S, Dunne DF, O’Grady E, Smethurst A, Terlizzo M, Malik HZ, Fenwick SW, Poston GJ: Radiological assessment of response to neoadjuvant transcatheter hepatic therapy with irinotecan-eluting beads (DEBIRI ${ }^{\circledR}$ ) for colorectal liver metastases does not predict tumour destruction or long-term outcome. Eur J Surg Oncol 2013;39:1122-1128.

5 Jones RP, Jackson R, Dunne DF, Malik HZ, Fenwick SW, Poston GJ, Ghaneh P: Systematic review and metaanalysis of follow-up after hepatectomy for colorectal liver metastases. Br J Surg 2012;99:477-486.

6 Kokudo N, Tada K, Seki M, Ohta H, Azekura K, Ueno M, Matsubara T, Takahashi T, Nakajima T, Muto T: Anatomical major resection versus nonanatomical limited resection for liver metastases from colorectal carcinoma. Am J Surg 2001;181:153-159.

7 Mise Y, Aloia TA, Brudvik KW, Schwarz L, Vauthey JN, Conrad C: Parenchymal-sparing Hepatectomy in Colorectal Liver Metastasis Improves Salvageability and Survival. Ann Surg 2016;263:146-152.

8 Torzilli G, Procopio F, Botea F, Marconi M, Del Fabbro D, Donadon M, Palmisano A, Spinelli A, Montorsi M: One-stage ultrasonographically guided hepatectomy for multiple bilobar colorectal metastases: a feasible and effective alternative to the 2-stage approach. Surgery 2009;146:60-71.

9 Kingham TP, Correa-Gallego C, D’Angelica MI, Gönen M, DeMatteo RP, Fong Y, Allen PJ, Blumgart LH, Jarnagin WR: Hepatic parenchymal preservation surgery: decreasing morbidity and mortality rates in 4,152 resections for malignancy. J Am Coll Surg 2015;220:471-479.

10 Stättner S, Jones RP, Yip VS, Buchanan K, Poston GJ, Malik HZ, Fenwick SW: Microwave ablation with or without resection for colorectal liver metastases. Eur J Surg Oncol 2013;39:844-849.

11 Tanis E, Nordlinger B, Mauer M, Sorbye H, van Coevorden F, Gruenberger T, Schlag PM, Punt CJ, Ledermann J, Ruers TJ: Local recurrence rates after radiofrequency ablation or resection of colorectal liver metastases. Analysis of the European Organisation for Research and Treatment of Cancer \#40004 and \#40983. Eur J Cancer 2014;50:912-919.

12 Mitry E, Fields AL, Bleiberg H, Labianca R, Portier G, Tu D, Nitti D, Torri V, Elias D, O'Callaghan C, Langer B, Martignoni G, Bouché O, Lazorthes F, Van Cutsem E, Bedenne L, Moore MJ, Rougier P: Adjuvant chemotherapy after potentially curative resection of metastases from colorectal cancer: a pooled analysis of two randomized trials. J Clin Oncol 2008;26:4906-4911. 
13 Nordlinger B, Sorbye H, Glimelius B, Poston GJ, Schlag PM, Rougier P, Bechstein WO, Primrose JN, Walpole ET, Finch-Jones M, Jaeck D, Mirza D, Parks RW, Collette L, Praet M, Bethe U, Van Cutsem E, Scheithauer W, Gruenberger T, EORTC Gastro-Intestinal Tract Cancer Group, Cancer Research UK, Arbeitsgruppe Lebermetastasen und-tumoren in der Chirurgischen Arbeitsgemeinschaft Onkologie (ALM-CAO), Australasian Gastro-Intestinal Trials Group (AGITG), Fédération Francophone de Cancérologie Digestive (FFCD): Perioperative chemotherapy with FOLFOX4 and surgery versus surgery alone for resectable liver metastases from colorectal cancer (EORTC Intergroup trial 40983): a randomised controlled trial. Lancet 2008;371:1007-1016.

14 Nordlinger B, Sorbye H, Glimelius B, Poston GJ, Schlag PM, Rougier P, Bechstein WO, Primrose JN, Walpole ET, Finch-Jones M, Jaeck D, Mirza D, Parks RW, Mauer M, Tanis E, Van Cutsem E, Scheithauer W, Gruenberger T, EORTC Gastro-Intestinal Tract Cancer Group, Cancer Research UK, Arbeitsgruppe Lebermetastasen und-tumoren in der Chirurgischen Arbeitsgemeinschaft Onkologie (ALM-CAO), Australasian Gastro-Intestinal Trials Group (AGITG), Fédération Francophone de Cancérologie Digestive (FFCD): Perioperative FOLFOX4 chemotherapy and surgery versus surgery alone for resectable liver metastases from colorectal cancer (EORTC 40983): long-term results of a randomised, controlled, phase 3 trial. Lancet Oncol 2013;14:1208-1215.

15 Sorbye H, Mauer M, Gruenberger T, Glimelius B, Poston GJ, Schlag PM, Rougier P, Bechstein WO, Primrose JN, Walpole ET, Finch-Jones M, Jaeck D, Mirza D, Parks RW, Collette L, Van Cutsem E, Scheithauer W, Lutz MP, Nordlinger B, EORTC Gastro-Intestinal Tract Cancer Group, Cancer Research UK (CRUK), Arbeitsgruppe Lebermetastasen und-tumoren in der Chirurgischen Arbeitsgemeinschaft Onkologie (ALM-CAO), Australasian Gastro-Intestinal Trials Group (AGITG), Fédération Francophone de Cancérologie Digestive (FFCD): Predictive factors for the benefit of perioperative FOLFOX for resectable liver metastasis in colorectal cancer patients (EORTC Intergroup Trial 40983) [EORTC Intergroup Trial 40983]. Ann Surg 2012;255:534-539.

16 Jones RP, Malik HZ, Fenwick SW, Poston GJ: Perioperative chemotherapy for resectable colorectal liver metastases: where now? Eur J Surg Oncol 2013;39:807-811.

17 Ychou M, Hohenberger W, Thezenas S, Navarro M, Maurel J, Bokemeyer C, Shacham-Shmueli E, Rivera F, Kwok-Keung Choi C, Santoro A: A randomized phase III study comparing adjuvant 5-fluorouracil/folinic acid with FOLFIRI in patients following complete resection of liver metastases from colorectal cancer. Ann Oncol 2009;20:1964-1970.

18 Primrose J, Falk S, Finch-Jones M, Valle J, O’Reilly D, Siriwardena A, Hornbuckle J, Peterson M, Rees M, Iveson T, Hickish T, Butler R, Stanton L, Dixon E, Little L, Bowers M, Pugh S, Garden OJ, Cunningham D, Maughan T, Bridgewater J: Systemic chemotherapy with or without cetuximab in patients with resectable colorectal liver metastasis: the New EPOC randomised controlled trial. Lancet Oncol 2014;15:601-611.

19 Nordlinger B, Poston GJ, Goldberg RM: Should the Results of the New EPOC Trial Change Practice in the Management of Patients With Resectable Metastatic Colorectal Cancer Confined to the Liver? J Clin. Oncol 2015;33:241-243.

20 Tanaka K, Shimada H, Matsuo K, Nagano Y, Endo I, Sekido H, Togo S: Outcome after simultaneous colorectal and hepatic resection for colorectal cancer with synchronous metastases. Surgery 2004;136:650-659.

21 Adam R, Bhangui P, Poston G, Mirza D, Nuzzo G, Barroso E, Ijzermans J, Hubert C, Ruers T, Capussotti L, Ouellet JF, Laurent C, Cugat E, Colombo PE, Milicevic M: Is perioperative chemotherapy useful for solitary, metachronous, colorectal liver metastases? Ann Surg 2010 Nov;252:774-787.

22 Poston GJ, Adam R, Alberts S, Curley S, Figueras J, Haller D, Kunstlinger F, Mentha G, Nordlinger B, Patt Y, Primrose J, Roh M, Rougier P, Ruers T, Schmoll HJ, Valls C, Vauthey NJ, Cornelis M, Kahan JP: Onco Surge: a strategy for improving resectability with curative intent in metastatic colorectal cancer. J Clin Oncol 2005;23:7125-7134.

23 Dunne DF, Jones RP, Lythgoe DT, Pilkington FJ, Palmer DH, Malik HZ, Poston GJ, Lacasia C, Jack S, Fenwick SW: Cardiopulmonary exercise testing before liver surgery. J Surg Oncol 2014;110:439-444.

24 Jones RP, Vauthey JN, Adam R, Rees M, Berry D, Jackson R, Grimes N, Fenwick SW, Poston GJ, Malik HZ: Effect of specialist decision-making on treatment strategies for colorectal liver metastases. Br J Surg 2012;99:1263-1269.

25 Morris EJ, Forman D, Thomas JD, Quirke P, Taylor EF, Fairley L, Cottier B, Poston G: Surgical management and outcomes of colorectal cancer liver metastases. Br J Surg 2010;97:1110-1118.

26 Ruers T, Punt C, Van Coevorden F, Pierie JP, Borel-Rinkes I, Ledermann JA, Poston G, Bechstein W, Lentz MA, Mauer M, Van Cutsem E, Lutz MP, Nordlinger B, EORTC Gastro-Intestinal Tract Cancer Group, Arbeitsgruppe Lebermetastasen und-tumoren in der Chirurgischen Arbeitsgemeinschaft Onkologie (ALM-CAO) and the National Cancer Research Institute Colorectal Clinical Study Group (NCRI CCSG): Radiofrequency ablation combined with systemic treatment versus systemic treatment alone in patients with non-resectable colorectal liver metastases: a randomized EORTC Intergroup phase II study (EORTC 40004) [EORTC 40004]. Ann Oncol 2012;23:2619-2626.

27 Ruers T, Punt CJ, van Coevorden F, Pierie JP, Rinkes IB, Ledermann J, et al: 0-018 Radiofrequency ablation [RFA] combined with chemotherapy for unresectable colorectal liver metastases [CRC LM]: Longterm survival results of a randomised phase II study of the EORTC-NCRI CCSG-ALM Intergroup is 40004 [CLOCC]. Ann Oncol 2015;26(suppl 4):iv114-iv5. 